\title{
LAND COVER AND TEMPERATURE IMPLICATIONS FOR THE SEASONAL EVAPOTRANSPIRATION IN EUROPE
}

\author{
Mărgărit-Mircea NISTOR ${ }^{1^{*}}$, Titus Cristian MAN ${ }^{2}$, Mostafa Ali BENZAGHTA $^{3}$, \\ Nikhil NEDUMPALLILE VASU ${ }^{4}$, Ştefan DEZSI ${ }^{2}$, Richard KIZZA ${ }^{1}$
}

DOI: 10.21163/GT_2018.131.09

\begin{abstract}
:
Land cover and spatial variation of seasonal temperature may contribute to different evapotranspiration rates between the European regions. In order to assess the integral effect of land cover and climate on water resources, we implemented a procedure which allows defining favorability areas to high rate of evapotranspiration. Seasonal mean air temperature for the present (2011-2040) and future (2041-2070) combined with the seasonal crop coefficients of current future projections of land cover for the 2040s have been used to evaluate the various degrees of evapotranspiration at European scale. Extremely high and very high degree of evapotranspiration tendency were verified for Southern, Eastern, Western and Central of Europe during the mid-season period. The low and very low evapotranspiration favorability were found in the Scandinavian Peninsula and in the Alps, Dinarics, and Carpathian during the present period in all the seasons. In the cold season, the land cover favorability to evapotranspiration (LCFE) is low and very low in almost the whole Europe. These findings indicate that the southern and western regions of Europe are facing low water availability, decrease in surface water flow, and possible long periods of drought in the summers.
\end{abstract}

Key-words: Crop coefficients, Climate change, Evapotranspiration favorability, Europe.

\section{INTRODUCTION}

Europe is a dynamic continent from many points of view. Changes in land cover pattern after the 1980s and urban development were observed continuously in many locations, especially around the capitals and larger cities. Natural places, such as mountain areas and the wetlands indicate a low degree of urbanization, but at the same time, these regions are facing global natural changes. The climate is warming (Haeberli et al, 1999; IPCC, 2001) and most of the glaciers and ice lands have been retreating continuously in the last decades (Kargel et al, 2005; Oerlemans, 2005; Shahgedanova et al, 2005; Dong et al, 2013; Xie et al, 2013; Elfarrak et al, 2014; Nistor \& Petcu, 2015). The main variations at

\footnotetext{
${ }^{I}$ Nanyang Technological University, School of Civil and Environmental Engineering, 639798, Singapore;

*Corresponding author email: margarit@ntu.edu.sg; Lastco-author email: kizz0001@e.ntu.edu.sg

${ }^{2}$ Faculty of Geography, University of Babeş-Bolyai, 400006, Cluj-Napoca, Romania, emails: man.titus@yahoo.com,stefan.dezsi@ubbcluj.ro

${ }^{3}$ Soil and Water Department, Faculty of Agriculture, Sirte University, 054, Sirte, Libya, email: benzaghta69@gmail.com

${ }^{4}$ British Geological Survey, Keyworth, Nottinghamshire, NG125GG, UK. email: nikil.nv@gmail.com
} 
global and continental scales come from changes in the mean air temperature which are expected to increase for the mid-century. Moreover, the natural systems are often influenced by climate change (Parmesan \& Yohe, 2003; Aguilera \& Murillo, 2009; Yustres et al, 2013; Jiménez Cisneros et al, 2014; Kløve et al, 2014). The most affected resources by climate change are the water resources, both freshwater and groundwater (Loàiciga et al, 2000; Bachu \& Adams, 2003; Brouyère et al, 2004; Campos et al, 2013; Nistor et al, 2014; Prăvălie et al, 2014). The ecosystems are also facing climate change in many places from the globe, with significant changes in the biodiversity composition as well (Nistor, 2013; Nistor \& Petcu, 2014).

In the last decades, climate change effects on water resources were claimed in details through numerous examples, regarding water quality and water quantity (Jiménez Cisneros et al, 2014). More than this, the climate change impact together with the land cover contributes to the hydrologic sensitivity of an area. Öztürk et al (2013) modelled the impact of land use on rural watershed from northern Turkey, mentioning that the hydrological processes influence watersheds with respect to meteorology, surfaces and underground characteristics. Thus, land cover represents a crucial factor in evapotranspiration, runoff, infiltration, and groundwater recharge (Öztürk et al, 2013). The runoff and evapotranspiration have been studied by Čenčur Curk et al (2014) in South-East Europe for groundwater vulnerability. Cheval et al (2017) used regional coupled models in the determination of aridity in South-Eastern Europe. In their survey, climate change and land cover have been carefully studied and several areas with high vulnerability were depicted, especially in locations with less water availability, aquifers characteristics, and pollution load index of each land cover type. Thus, an important role of surface and groundwater resources come from the evapotranspiration phenomena, which shows an essential concern for water balance and water surplus (Li et al, 2007; Rosenberry et al, 2007; Gowda et al, 2008). At the temperate zone, climate and land cover are directly responsible for evapotranspiration, a fact for which many investigations on this topic have been carried out in recent years by Ambas \& Baltas (2012), Nistor \& Porumb-Ghiurco (2015), Nistor et al (2016a), Nistor et al (2016b), Nistor et al (2017a), Nistor et al (2017b). They applied an original method, which assesses crop evapotranspiration at regional scale based on seasonal potential evapotranspiration, and standard seasonal crop coefficients $(\mathrm{Kc})$ presented in the FAO Paper no. 56 (Allen et al, 1998; Allen, 2000). Considering this methodology, changes of climate and land cover could be problematic for many natural systems of the regions, e.g. groundwater and surface hydrology, agriculture and orchards, desertification in the dry grassland areas. Nistor (2016) determined the seasonal Kc for the Paris metropolitan area. In the Kingdom of Saudi Arabia, Güçlü et al (2017) calculated evapotranspiration using a regional fuzzy chain model. Based on the REMO and ALADIN regional climate models, Ladányi et al (2015) analyzed the drought hazard in south-central Hungary, in the Kiskunság National Park. Gao et al (2007) estimated the actual evapotranspiration over China during 1961-2002. The spatial-temporal characteristics of the actual evapotranspiration have been completed by Gao et al (2012) in the Haihe River basin from East China.

Regarding heterogeneity of the European continent and the current climate change, significant changes in the climate parameters such as temperature, rainfall, and evapotranspiration are expected for the mid-century. Considering the land cover projections for Europe, different visions over the economy, agriculture, industry, and natural ecosystems may be drawn. A method, which combines mean air temperature and land cover 
to evaluate the synergy of climate and vegetation pattern on evapotranspiration parameter, could be a new issue for Europe, from many points of view.

The scope of the present paper is to propose a methodology to assess the effect of seasonal temperature and seasonal $\mathrm{Kc}$ on evapotranspiration following the spatial-temporal scale of Europe during 2011-2070. The second scope is to identify the favorability areas with different degrees for the evapotranspiration. Our results contribute both to the specialty literature of Europe and may be useful to policymakers for decision making
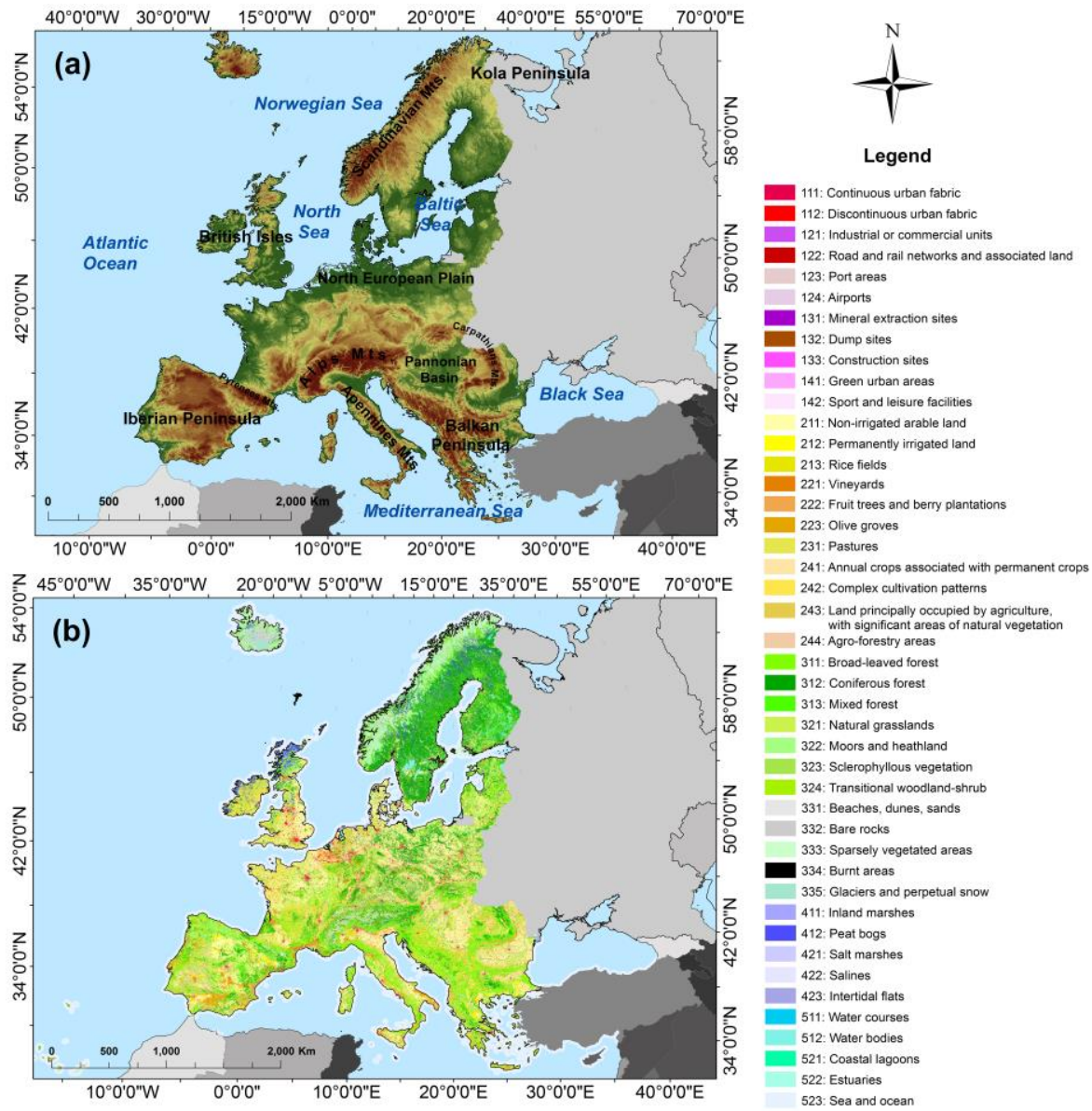

Fig. 1. (a). The physical map of European continent. (b). Land cover of the Europe. regarding agricultural management and environmental planning.

\section{STUDY AREA}

The analyzed territory in this paper includes the Western, Northern, Southern, and Central regions of Europe. To these lands are added the British Islands and some islands from the Mediterranean Sea, e.g. Sardinia, Corsica, Aegean Islands, Baleares Islands. The 
eastern sides of the continent, such as Russian, Ukraine, and Belarus have not been investigated here due to lack of land cover data. For future projections, Switzerland, Norway, and countries from the West of Balkan Peninsula do not have already completed land cover patterns. For Iceland, climate data are absent. The morphology of Europe indicates numerous landforms in correspondence with the main reliefs that are found in the territory (Fig. 1a). The highlands of the continent consist mainly of mountain chains: Alps Range, Carpathian Range, Dinarics Mountains, Pyrenees Mountains, Scandinavian Mountains and Apennines Mountains. The lowlands overlap to the North European Plain, Pannonian basin, South of British Islands, Romanian Plain, Po Plain. Between mountains and plains, hilly and plateau reliefs could be found. The coastline of Europe shows very articulated promontories, sea bays, fjords, and islands.

The geographical position, in the northern hemisphere between $34^{\circ} 35^{\prime}$ to $80^{\circ} 42^{\prime}$ latitude $\mathrm{N}$ and $8^{\circ} 59^{\prime}$ longitude $\mathrm{W}$ to $66^{\circ} 42^{\prime}$ longitude $\mathrm{E}$ and the presence of the Atlantic Ocean in the West are the main factors which influence the climate of Europe. Thus, in the North, there is more of a Baltic climate, while in the South, the Saharan and Mediterranean influences are felt. The western side of Europe together with the British Islands have more oceanic influences and in the eastern parts, the continentality is more presented. The relief arrangement and the regional wind movements induce local climate such as mountain climate, Pontic influence near the Black Sea and the transition climate between oceanic and continental could be identified in the East-central parts. The mean air temperature range from $-12{ }^{\circ} \mathrm{C}$ to $21{ }^{\circ} \mathrm{C}$ and the maximum mean precipitation reaches $3500 \mathrm{~mm}$ year ${ }^{-1}$. According to the Köppen-Geiger climate classification, the Cfa climate characterized by hot summers and a fully humid period was depicted in the Central, North-central, Southern, and Southeastern sides (Kottek et al, 2006). In the Scandinavian Peninsula and in the northeastern extremities, the Dfc class (cool climate) has been observed. The eastern and southeastern areas of Europe have Dfa and Dfb climates, which implies a cool climate but with hot and warm summers. The Csb climate was identified in the North of the Iberian Peninsula while in the South of the Iberian Peninsula, the Csa climate was depicted (Kottek et al, 2006). The high mountains and in the Scandinavian territory, the tundra climate is presented due to low temperatures (Kottek et al, 2006).

According to relief and climate, the vegetation of Europe is very diversified (Fig. 1b). The plains and hilly areas are favorable for agricultural lands, herbaceous vegetation, and grasslands. In the mountain areas up to $1800 \mathrm{~m}$ altitude, there extends the coniferous vegetation. Broad-leaved and mixed forests grow both in the mountains and hilly areas. The main species of trees that can be found in Europe include the oak (Quercus), elms (Ulmus), beech (Fagus), and hornbeam (Carpinus) (European Environment Agency, 2007). Transnational woodland, shrubs and pasture predominantly cover the elevated areas (over $1800 \mathrm{~m}$ ). The coastal areas are often covered by green vegetation of various types of trees and sclerophyllous vegetation. Deltas, lagoons, and marshes are specifically for the low coastal areas such as Rhone Delta, Po Delta, and Danube Delta. European coastlines do not miss artificial port areas, man-made infrastructure and dams.

\section{MATERIALS AND METHODS}

\subsection{Climate data}

In order to determine the seasonal temperature of Europe at a spatial scale, we used the climate models of temperature for 30 years related to 2011 to 2040 (present) and 2041-2070 (future). Andreas Hamann, from Alberta University, Canada, constructed these climate 
models at a very high resolution using the ANUSplin interpolation method. The mean monthly air temperature served to complete the raster datasets for four seasons according to the seasonal periods in the temperate zone but also in relationship with the growth plant calendar in Europe. The climate models were carried out based on the historical data from 1901 to 2013 followed the Mitchell \& Jones (2005) method.

The ClimateEU v4.63 software package has been used to complete the climate models. The CMIP5 multi-model dataset, related to the IPCC Assessment Report 5 (2013) have been considered for the future projections. Representative Concentration Pathway (RCP) 4.5 by $+1.4^{\circ} \mathrm{C}( \pm 0.5)$ for the 2050 s was used due to the global warming mean projections. The methodology of the models is exposed in a clear way by Hamann \& Wang (2005), Daly et al. (2006), Mbogga et al (2009), and Hamann et al (2013). For the present study, the climate models spatial resolution was set at $1 \mathrm{~km}^{2}$.
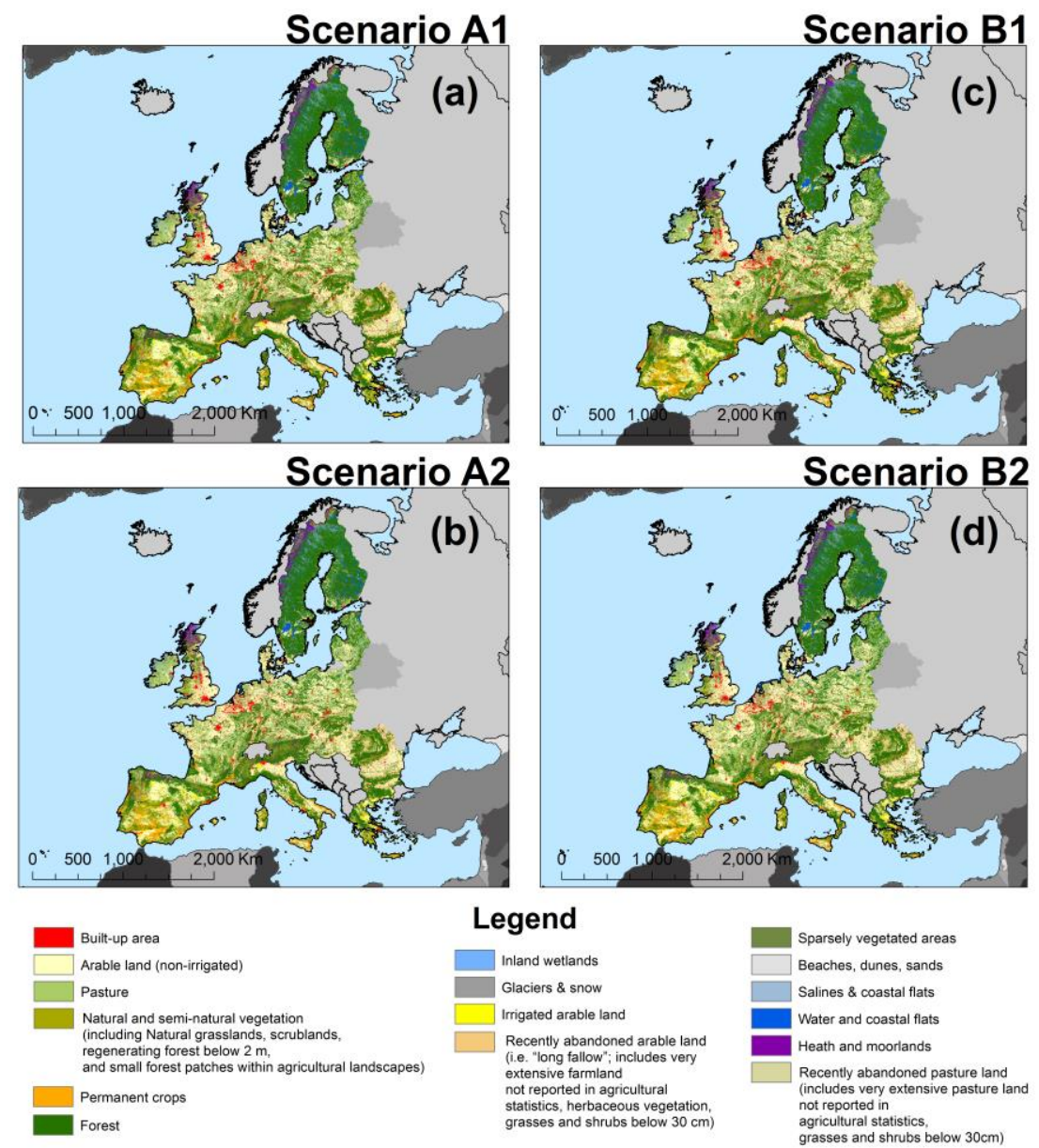

Fig. 2. Land cover projections of Europe. (a) Scenario A1. (b) Scenario A2. (c) Scenario B1. (d)

Scenario B2. Source: Sustainable futures for Europe's HERitage in CULtural landscapES" project (http://www.hercules-landscapes.eu/).

\subsection{Land cover data}


CORINE Land Cover raster data from 2012 at $250 \mathrm{~m}^{2}$ spatial resolution have been used to identify the main crops, shrubs and trees, and the land use in Europe. We agree with the CORINE Land Cover due to its georeferenced characteristics and the detailed classes up to $4^{\text {th }}$ level.

Table 1. Corine Land Cover classes and representative seasonal Kc coefficients in Europe during the present period.

\begin{tabular}{|c|c|c|c|c|c|}
\hline & Corine Land Cover & $\begin{array}{l}\text { Kc ini } \\
\text { season }\end{array}$ & $\begin{array}{l}\text { Kc mid } \\
\text { season }\end{array}$ & $\begin{array}{l}\text { Kc end } \\
\text { season }\end{array}$ & $\begin{array}{l}\text { Kc cold } \\
\text { season }\end{array}$ \\
\hline $\begin{array}{l}\text { CLC code } \\
2012 \\
\end{array}$ & CLC Description & Kclc & Kclc & Kclc & Kclc \\
\hline 111 & Continous urban fabric & 0.2 & 0.4 & 0.25 & - \\
\hline 112 & Discontinuous urban fabric & 0.1 & 0.3 & 0.2 & - \\
\hline 121 & Industrial or commercial units & 0.2 & 0.4 & 0.3 & - \\
\hline 122 & Road and rail networks and associated land & 0.15 & 0.35 & 0.25 & - \\
\hline 123 & Port areas & 0.3 & 0.5 & 0.4 & - \\
\hline 124 & Airports & 0.2 & 0.4 & 0.3 & - \\
\hline 131 & Mineral extraction sites & 0.16 & 0.36 & 0.26 & - \\
\hline 132 & Dump sites & 0.16 & 0.36 & 0.26 & - \\
\hline 133 & Construction sites & 0.16 & 0.36 & 0.26 & - \\
\hline 141 & Green urban areas & 0.12 & 0.32 & 0.22 & - \\
\hline 142 & Sport and leisure facilities & 0.1 & 0.3 & 0.2 & - \\
\hline 211 & Non-irrigated arable land & 1.1 & 1.35 & 1.25 & - \\
\hline 212 & Permanently irrigated land & 1.2 & 1.45 & 1.35 & - \\
\hline 213 & Rice fields & 1.05 & 1.2 & 0.6 & - \\
\hline 221 & Vineyards & 0.3 & 0.7 & 0.45 & - \\
\hline 222 & Fruit trees and berry plantations & 0.3 & 1.05 & 0.5 & - \\
\hline 223 & Olive groves & 0.65 & 0.7 & 0.65 & 0.5 \\
\hline 231 & Pastures & 0.4 & 0.9 & 0.8 & - \\
\hline 241 & Annual crops associated with permanent crops & 0.5 & 0.8 & 0.7 & - \\
\hline 242 & Complex cultivation patterns & 1.1 & 1.35 & 1.25 & - \\
\hline 243 & $\begin{array}{l}\text { Land principally occupied by agriculture, with } \\
\text { significant areas of natural vegetation }\end{array}$ & 0.7 & 1.15 & 1 & - \\
\hline 244 & Agro-forestry areas & 0.9 & 1.1 & 1.05 & 0.3 \\
\hline
\end{tabular}

Source: From Allen et al. (1998); Nistor and Porumb-Ghiurco (2015); Nistor (2017); Nistor et al. (2017) 
Table 1. Corine Land Cover classes and representative seasonal Kc coefficients in Europe during the present period (continue).

\begin{tabular}{clcccc}
\hline CLC code & Corine Land Cover & $\begin{array}{c}\text { Kc ini } \\
\text { season }\end{array}$ & $\begin{array}{c}\text { Kc mid } \\
\text { season }\end{array}$ & $\begin{array}{c}\text { Kc end } \\
\text { season }\end{array}$ & $\begin{array}{c}\text { Kc cold } \\
\text { season }\end{array}$ \\
\hline 312 & CLescription & Kclc & Kclc & Kclc & Kclc \\
312 & Broad-leaved forest & 1.3 & 1.6 & 1.5 & 0.6 \\
313 & Coniferous forest & 1 & 1 & 1 & 1 \\
321 & Nixed forest & 1.2 & 1.5 & 1.3 & 0.8 \\
322 & Moors and heathland & 0.3 & 1.15 & 1.1 & - \\
323 & Sclerophyllous vegetation & 0.8 & 1 & 0.95 & - \\
324 & Transitional woodland-shrub & 0.25 & 0.9 & 0.8 & - \\
331 & Beaches, dunes, sands & 0.8 & 1 & 0.95 & - \\
332 & Bare rocks & 0.2 & 0.3 & 0.25 & - \\
333 & Sparsely vegetated areas & 0.15 & 0.2 & 0.05 & - \\
334 & Burnt area & 0.4 & 0.6 & 0.5 & - \\
335 & Glaciers and perpetual snow & 0.1 & 0.15 & 0.05 & - \\
411 & Inland marshes & 0.48 & 0.52 & 0.52 & 0.48 \\
412 & Peat bogs & 0.15 & 0.45 & 0.8 & - \\
421 & Salt marshes & 0.1 & 0.4 & 0.75 & - \\
422 & Salines & 0.1 & 0.3 & 0.7 & - \\
423 & Intertidal flats & 0.1 & 0.15 & 0.05 & - \\
511 & Water courses & 0.3 & 0.7 & 1.3 & - \\
512 & Water bodies & 0.25 & 0.65 & 1.25 & - \\
521 & Coastal lagoons & 0.25 & 0.65 & 1.25 & - \\
522 & Estuaries & 0.3 & 0.7 & 1.3 & - \\
523 & Sea and ocean & 0.25 & 0.65 & 1.25 & - \\
\hline & & 0.4 & 0.8 & 1.4 & - \\
\hline
\end{tabular}

Source: From Allen et al. (1998); Nistor and Porumb-Ghiurco (2015); Nistor (2017); Nistor et al. (2017)

This database is available on Copernicus Land Monitoring Services (2012) website. The projections of future land cover for the main European countries were carried out in the "Sustainable futures for Europe's HERitage in CULtural landscapES" (Hercules) project, GA no. 603447 (Schulp et al, 2015). The Hercules models offer a spatial vision of the land cover dynamics based on the fourteen trajectories in the land cover trend. These trajectories incorporate the macro-economic and land use modes taking into account urbanization, agriculture, and forestry. The "Landscape Character Index", extracted from various landscapes such as land use intensity, structures, and patterns (Schulp et al, 2015) was considered during mapping of the future land cover. In the present paper, we used the projections of A1, A2, B1, and B2 land cover scenarios for the 2040s, which illustrate sixteen classes of land types (Fig. 2). Access to these scenarios could be done through the Hercules website (http://www.hercules-landscapes.eu/). Entire procedure to obtain the land cover models is exposed in Report no. 1 of the Hercules project (Schulp et al, 2015). All 
maps were set at $1 \mathrm{X} 1 \mathrm{~km}$ to be in line with the climate models resolution. The ArcGIS environment was used for this investigation due to its reliability in spatial analysis of territory (Chaieb et al, 2017; Nistor \& Petcu, 2015).

\subsection{Seasonal crop coefficients (Kc)}

Each vegetation type has an evapotranspiration capacity called Kc. In order to calculate the crop evapotranspiration, Allen et al (1998) used the methodology based on standard Kc. These coefficients have been calculated both for single and dual crops, at different latitudes and in different climate types. According to Allen et al (1998), we set the seasonal Kc for the four seasons specific in the temperate zone. In the urban areas and bare soils, Grimmond \& Oke (1999) completed the Kc in several cities and locations from the United States. In the European regions, such as Pannonian basin and South East Europe, Nistor et al (2017a) and Nistor et al (2017b) analyzed crop evapotranspiration at spatial scale incorporating climate models and land cover data. They provided the Kc values for CORINE land cover classes and they explained the time shifts for the four seasons in their study area.

Here, we adopted the above methodology to assess the Kc values both for the present land cover and for the future. We agree with four seasons like initial season $\left(\mathrm{K}_{\mathrm{c} \text { ini }}\right)$ during March, April and May, the mid-season $\left(\mathrm{K}_{\mathrm{c} \text { mid }}\right)$ during June, July and August, the end season $\left(\mathrm{K}_{\mathrm{c} \text { end }}\right)$ during September and October, and the cold season $\left(\mathrm{K}_{\mathrm{c} \text { cold }}\right)$ during January, February, November, and December. These periods were set first by Nistor \& PorumbGhiurco (2015) who proposed the regional methodology at regional scale for EmiliaRomagna region. Further, Nistor et al (2016b) applied the same procedure for the Carpathian region. The stages, periods and the standard Kc values may slightly vary from place to place, with respect to latitude and local climate.

Table 1 reports the seasonal values of Kc used in this paper for the present period while Table 2 illustrates the kc values for the projected land cover scenarios.

\begin{tabular}{|c|c|c|c|c|c|c|c|c|}
\hline & & & \multicolumn{6}{|c|}{ Crop coefficient } \\
\hline & & \multirow{3}{*}{$\begin{array}{c}\text { Susceptibility } \\
\text { degree }\end{array}$} & $0-2$ & $0.21-0.6$ & $0.61-0.8$ & $0.81-1$ & $1.01-1.3$ & $>1.3$ \\
\hline \multirow{2}{*}{\multicolumn{2}{|c|}{ Temperature $\left[{ }^{\circ} \mathrm{C}\right]$}} & & Very low & Low & Medium & High & Very high & Extremely high \\
\hline & & & & & & & & \\
\hline Very cool & $<0$ & Very low & Very low & Very low & Very low & Very low & Very low & Very low \\
\hline Cool & $0-4$ & Low & Very low & Low & Low & Medium & Medium & Medium \\
\hline Temperate & $5-10$ & Medium & Low & Low & Medium & Medium & High & High \\
\hline Warm & $11-15$ & High & Low & Medium & Medium & High & Very high & Very high \\
\hline Hot & $16-20$ & Very high & Medium & Medium & High & Very high & Very high & Extremely high \\
\hline \multirow[t]{3}{*}{ Very hot } & $>20$ & Xtremely high & High & High & Very high & Very high & Extremely high & Extremely high \\
\hline & & & \multicolumn{6}{|c|}{ Susceptibility degree for evapotranspiration } \\
\hline & & & Very low & Low & Medium & High & Very high & Extremely hig \\
\hline
\end{tabular}

Fig. 3. The inference matrix used to assess the LCFE in Europe. 
Table 2. Corine Land Cover classes and representative seasonal Kc coefficients used for the future scenarios in Europe.

\begin{tabular}{|c|c|c|c|c|c|}
\hline & Corine Land Cover & $\begin{array}{l}\text { Kc ini } \\
\text { season }\end{array}$ & $\begin{array}{l}\text { Kc mid } \\
\text { season }\end{array}$ & $\begin{array}{l}\text { Kc end } \\
\text { season }\end{array}$ & $\begin{array}{l}\text { Kc cold } \\
\text { season }\end{array}$ \\
\hline $\begin{array}{c}\text { CLC } \\
\text { projection } \\
\text { code } \\
\end{array}$ & CLC Description & Kclc & Kclc & Kclc & Kclc \\
\hline 0 & Built-up area & 0.16 & 0.36 & 0.26 & - \\
\hline 1 & Arable land (non-irrigated) & 1.1 & 1.35 & 1.25 & - \\
\hline 2 & Pasture & 0.4 & 0.9 & 0.8 & - \\
\hline 3 & $\begin{array}{l}\text { Natural and semi-natural vegetation } \\
\text { (including Natural grasslands, } \\
\text { scrublands, regenerating forest } \\
\text { below } 2 \mathrm{~m} \text {, and small forest patches } \\
\text { within agricultural landscapes) }\end{array}$ & 0.45 & 1.1 & 1 & - \\
\hline 4 & Inland wetlands & 0.15 & 0.45 & 0.8 & - \\
\hline 5 & Glaciers and snow & 0.48 & 0.52 & 0.52 & 0.48 \\
\hline 6 & Irrigated arable land & 1.2 & 1.45 & 1.35 & - \\
\hline 7 & $\begin{array}{l}\text { Recently abandoned arable land (i.e. } \\
\text { "long fallow"; includes very } \\
\text { extensive farmland not reported in } \\
\text { agricultural statistics, herbaceous } \\
\text { vegetation, grasses and shrubs below } \\
30 \mathrm{~cm} \text { ) }\end{array}$ & 0.3 & 1.15 & 1.1 & - \\
\hline 8 & Permanent crops & 0.5 & 0.8 & 0.7 & - \\
\hline 10 & Forest & 1.2 & 1.5 & 1.3 & 0.8 \\
\hline 11 & Sparsely vegetated areas & 0.4 & 0.6 & 0.5 & - \\
\hline 12 & Beaches, dunes and sands & 0.2 & 0.3 & 0.25 & - \\
\hline 13 & Salines & 0.1 & 0.15 & 0.05 & - \\
\hline 14 & Water and coastal flats & 0.3 & 0.7 & 1.3 & - \\
\hline 15 & Heathland and moorlands & 0.8 & 1 & 0.95 & - \\
\hline 16 & $\begin{array}{l}\text { Recently abandoned pasture land } \\
\text { (includes very extensive pasture land } \\
\text { not reported in agricultural statistics, } \\
\text { grasses and shrubs below } 30 \mathrm{~cm} \text { ) }\end{array}$ & 0.6 & 1 & 0.9 & - \\
\hline
\end{tabular}

Source: From Allen et al. (1998); Nistor and Porumb-Ghiurco (2015); Nistor (2017); Nistor et al. (2017)

\subsection{NISTOR-LCFE method for assessing the land cover favorability for evapotranspiration}

The goal of the survey is to assess the seasonal temperature and seasonal $\mathrm{Kc}$ for Europe and to determine a method, which defines the areas with different degrees of evapotranspiration favorability. New Implemented Spatial-Temporal On Regions-Land Cover Favorability to Evapotranspiration (NISTOR-LCFE) method has been set to map favorability areas to evapotranspiration, and accounting for both the seasonal mean air temperature and seasonal Kc values. NISTOR-LCFE approach is a new tool based on $6 \times 6$ 
matrix that provides six degrees of favorability and it is easy to implement at spatialtemporal scale. Nistor et al (2016a), Nistor \& Mîndrescu (2017) have used an appropriate survey by matrix application in the hydrology study. Firstly, we classify the evapotranspiration favorability based on temperature and Kc values in six-degree classes: very low, low, medium, high, very high, and extremely high. The classification was done according to previous studies and observed thresholds of seasonal temperature and $\mathrm{Kc}$ values that may influence the evapotranspiration phenomena. We agree with the matrix classification due to climate and hydrological processes that may occur at different temperatures, in various types of vegetation cover. Figure 3 shows the proposed matrix used in the present methodology.

\section{RESULTS}

The seasonal mean air temperature and seasonal Kc have been completed for Europe in two time shifts (present and future) on the basis of the presented methodology. Figure 4 depicts the seasonal temperature in Europe for the 2011-2040 and 2041-2070 according to the four seasons of crop development. During the initial season, the mean air temperature reaches high values (over $12{ }^{\circ} \mathrm{C}$ ) both in the present and in the future period, showing that the Iberian Peninsula, Pannonian basin, coastal areas of the Italian Peninsula, and in North of Balkan Peninsula are the regions more warm in this stage.

The low values (below $0^{\circ} \mathrm{C}$ ) of temperature during the initial season could be found in the Scandinavian Mountains, Alps Range, Carpathian Range, Dinaric Mountains, and in the North of Europe (Figs. 4a and 4b). In the mid-season period, the high values of mean air temperature exceed $26{ }^{\circ} \mathrm{C}$ in the areas of Po Plain, South of Iberian Peninsula, Aegean Islands, and in the southeastern sides of the Balkan Peninsula. For the 2041-2070 period, the areas with high temperature extend at spatial scale of West and East parts of Italy and in the North of Balkan Peninsula. The low values of temperature in the mid-season were registered in the Alps Range, Scandinavian Peninsula, and in the North of British Islands (Figs. 4c and 4d). The air temperature in the end season reaches values over $20{ }^{\circ} \mathrm{C}$ especially in the central and West Iberian Peninsula, West of Sardinia, South of Sicily, and in the Aegean Islands. In the future period, areas with high values of temperature extend in the coastline of the Italian Peninsula, Po Plain, South of France, and in the East of Balkan Peninsula. The low values of mean air temperature could be depicted in the mountain areas, North of Europe and North of British Islands (Figs. 4e and 4f). In the cold season, both models illustrate low values of air temperature (below $4{ }^{\circ} \mathrm{C}$ ) in most part of central, eastern, and northern Europe, and the mountain belts. Low values are also presented in the North of British Islands and some areas from the Balkan Peninsula, where the elevated heights are. During the cold season, the West and South of Europe, mainly the Atlantic coast of the Iberian Peninsula and the Mediterranean Islands register values around $10-13{ }^{\circ} \mathrm{C}$ of air temperature. Interestingly, the air temperature models indicate higher values for the future in all seasons (Figs. 4g and 4h). As we expected, the temperature changes are located in the South East, in the West and in the South of Europe and extend in the territory. 

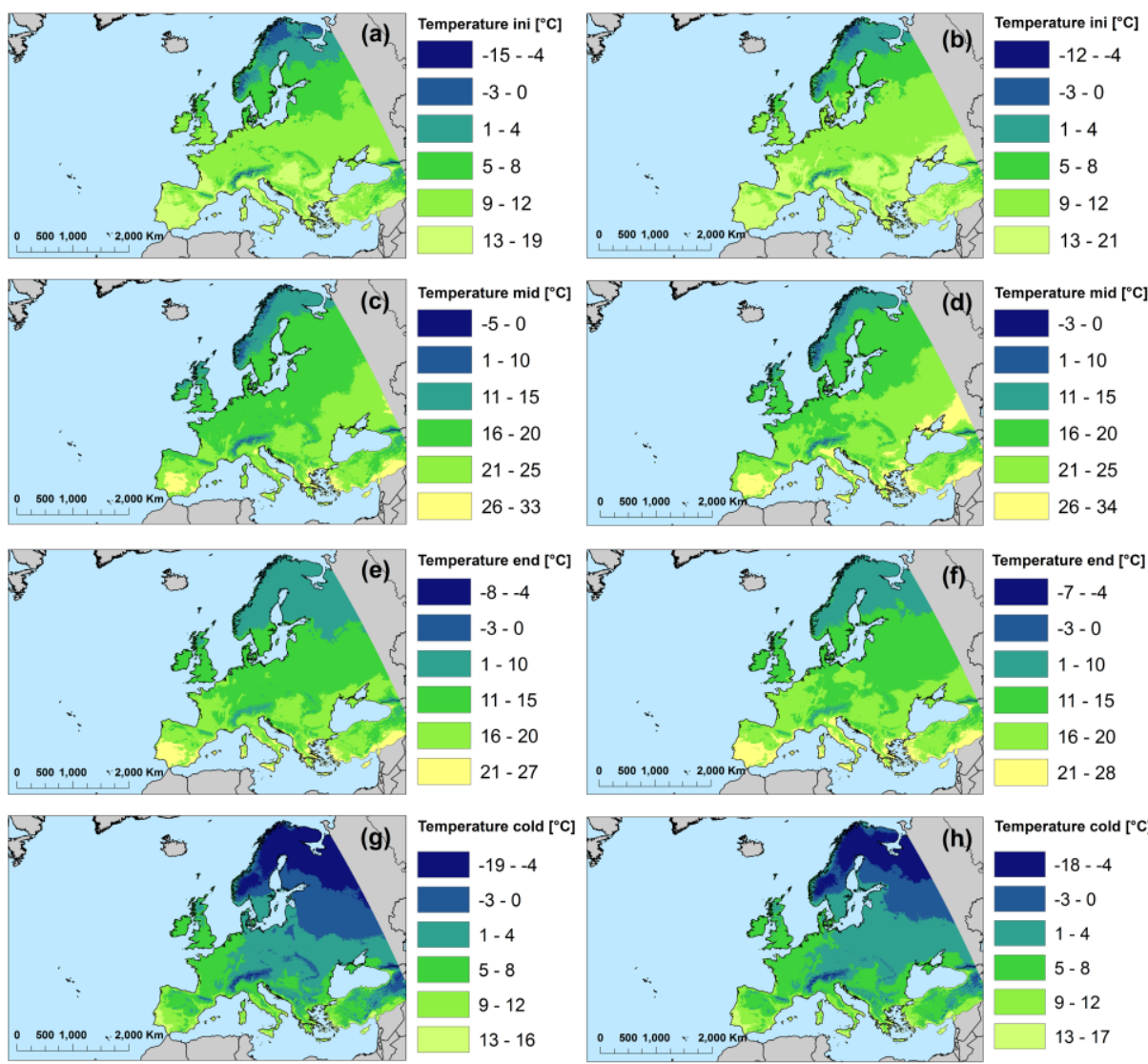

Fig. 4. Spatial distribution of seasonal air temperature in Europe. (a) Temperature for the initial (ini) season $(2011$ - 2040). (b) Temperature for the initial (ini) season $(2041$ - 2070). (c) Temperature for the mid-season (mid) $(2011$ - 2040). (d) Temperature for the mid-season (mid) $(2041-2070)$. (e) Temperature for the end season $(2011$ - 2040). (f) Temperature for the end season $(2041$ - 2070). (f) Temperature for the cold season $(2011-2040)$. (h) Temperature for the cold season $(2041-2070)$. 

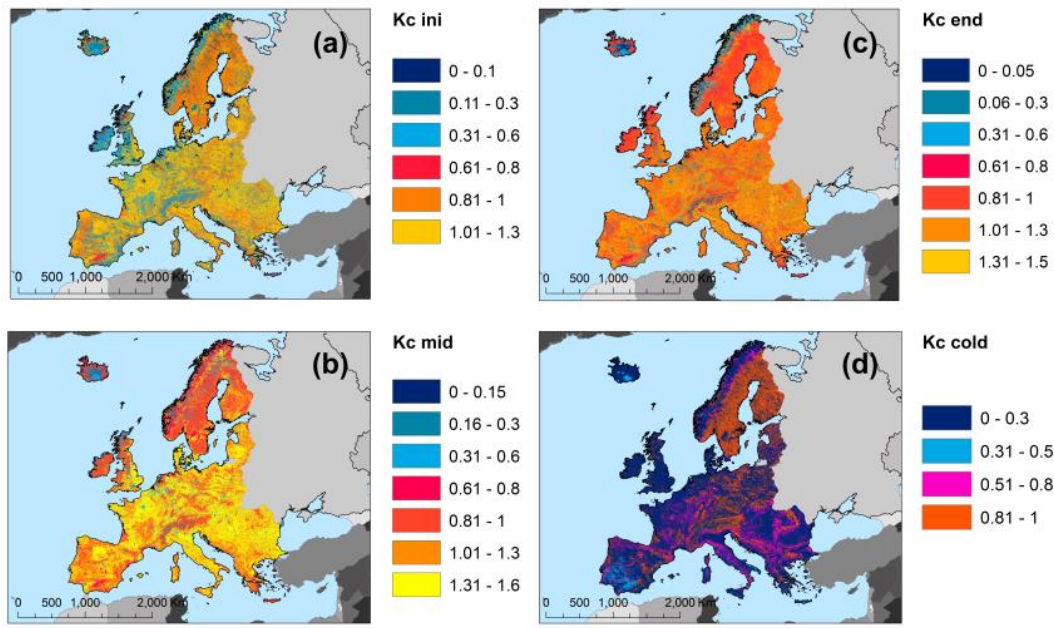

Kc cold

$0-0.3$

$0.31-0.5$

$0.51-0.8$

$0.81-1$

Fig. 5. Spatial distribution of Kc in Europe related to the present land cover. (a) Kc ini for the initial season. (b) Kc mid for the mid-season season. (c) Kc end for the end season. (d) Kc cold for the cold season.
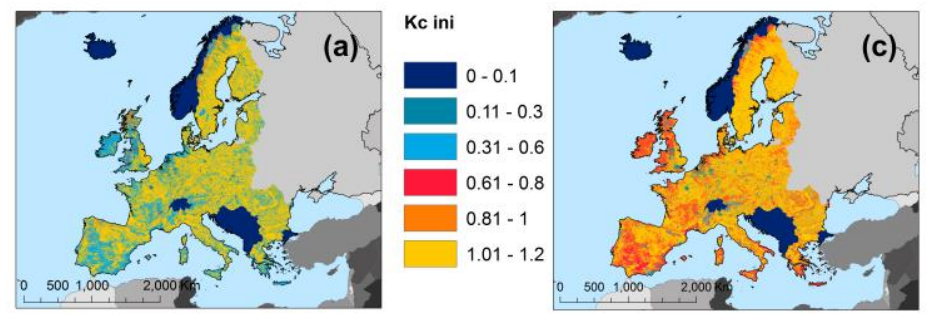

Kc end
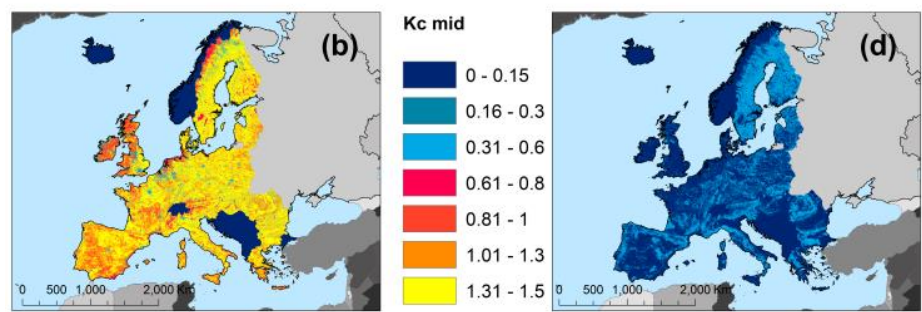

$0-0.48$

$0.49-0.8$

Fig. 6. Spatial distribution of $K_{c}$ in Europe related to the projection of scenario A1. (a) Kc ini for the initial season. (b) Kc mid for the mid-season season. (c) Kc end for the end season. (d) Kc cold for the cold season. 
During the present period, the Kc values range from 0 to 1.6 and register the maximum values in the mid-season stage (Fig. 5). The high values (1.31-1.6) could be depicted in the central, West, South-East, and South parts of Europe. The lower values of the Kc are related to the cold season when major parts of the continent have Kc values that range from 0 to 0.3 . During the initial and end seasons, the Kc values reach 1.3 and 1.5 respectively and mean $\mathrm{Kc}$ indicates values around $0.81-1$. The future land $\mathrm{Kc}$ illustrates values between 0 and 1.5, the maximum values being assigned for the mid-season stage. The cold season shows values up to 0.8 and the larger sides of the Europe have values of Kc between 0 and 0.48. Differences in the Kc pattern for the future are illustrated in Figures 6-9.

The LCFE map shows high and very high degree of favorability for the initial season in the East, South, and West sides of Europe, especially in the lowlands and on the coastal areas. The medium degree spread mainly in the Scandinavian Peninsula, Carpathian Mountains, Eastern Alps, central sides of the Europe, and in South of Iberian Peninsula. The low and very low LCFE were depicted in the North of Europe, North and West of the British Islands and in the mountain areas, especially in the Alps Range, Pyrenees, Central Apennines, and Dinaric Mountains. In the future period, increase in high degree has been observed in the Scandinavian Peninsula and in eastern Europe. The medium class of LCFE increases also for all scenarios in the Iberian Peninsula and in South of Europe, e.g. Sicily Island, Aegean Islands, South of Balkan Peninsula. Figure 10 illustrates the favorability degree in Europe related to the initial season.
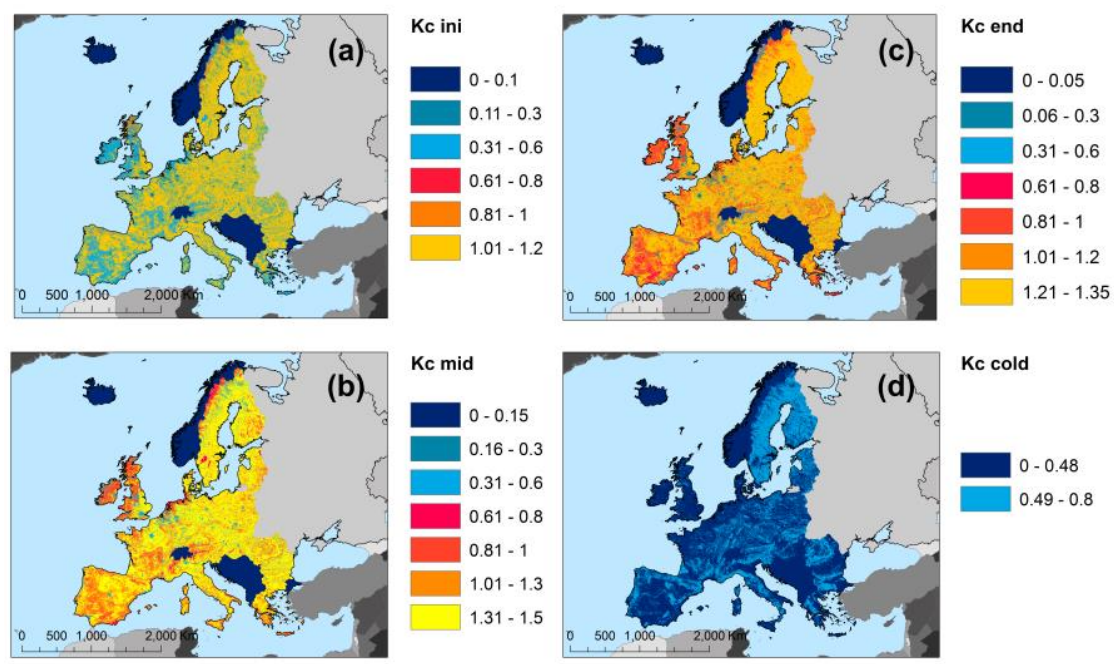

Kc cold

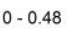

$0.49-0.8$

Fig. 7. Spatial distribution of Kc in Europe related to the projection of scenario A2. (a) Kc ini for the initial season. (b) Kc mid for the mid-season season. (c) Kc end for the end season. (d) Kc cold for the cold season. 

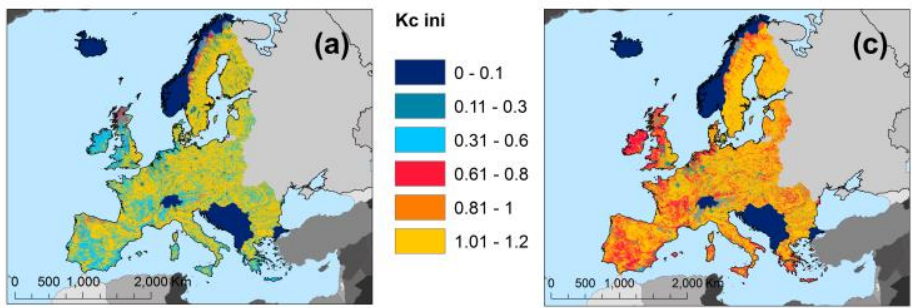

Kc end
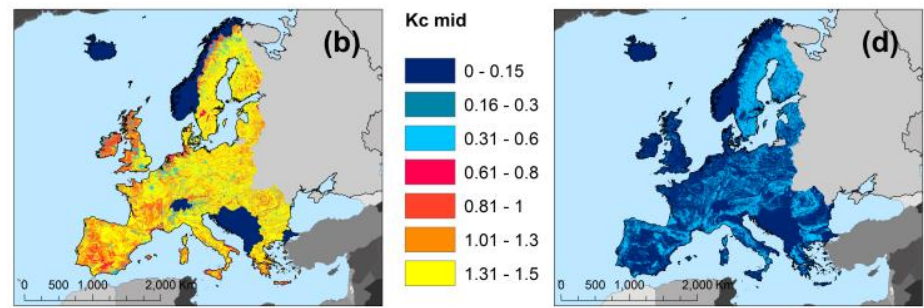

Kc cold

$0-0.48$

$0.48-0.8$

Fig. 8. Spatial distribution of Kc in Europe related to the projection of scenario B1. (a) Kc ini for the initial season. (b) Kc mid for the mid-season season. (c) Kc end for the end season. (d) Kc cold for the cold season.
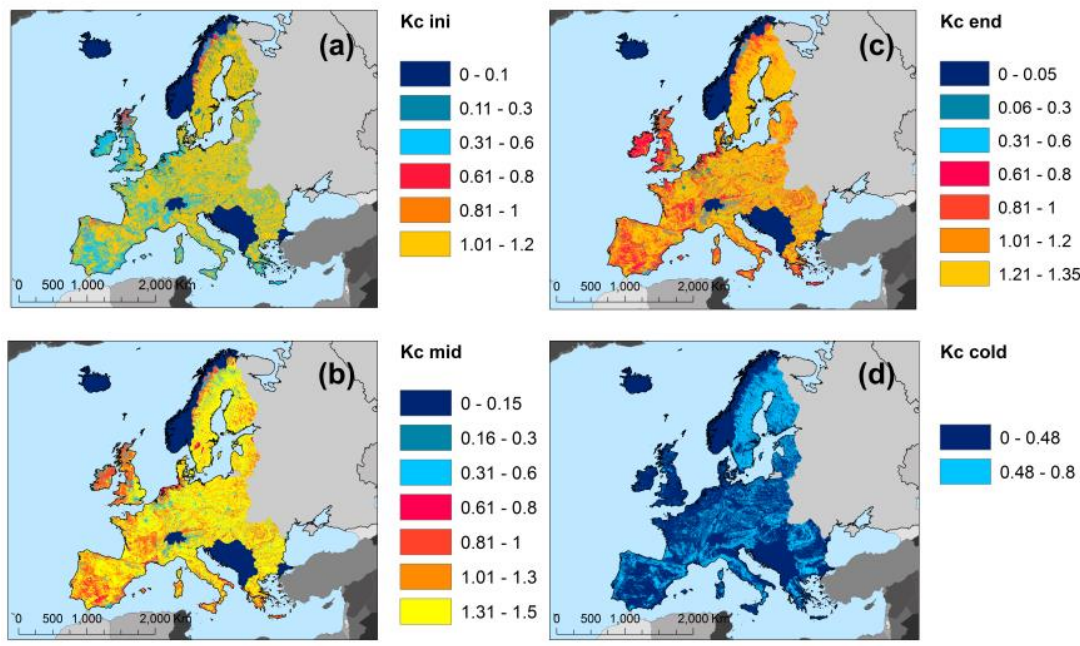

Kc cold

$0-0.48$

$0.48-0.8$

Fig. 9. Spatial distribution of Kc in Europe related to the projection of scenario B2. (a) Kc ini for the initial season. (b) Kc mid for the mid-season season. (c) Kc end for the end season. (d) Kc cold for the cold season. 


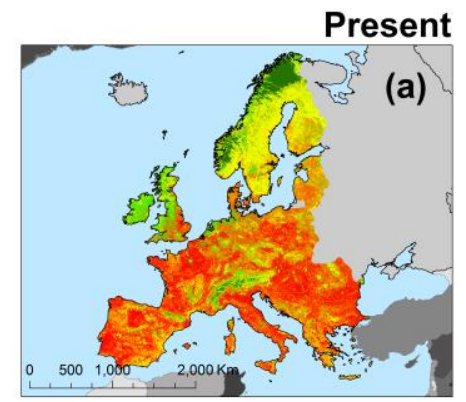

\section{Favorability degree (ini)}
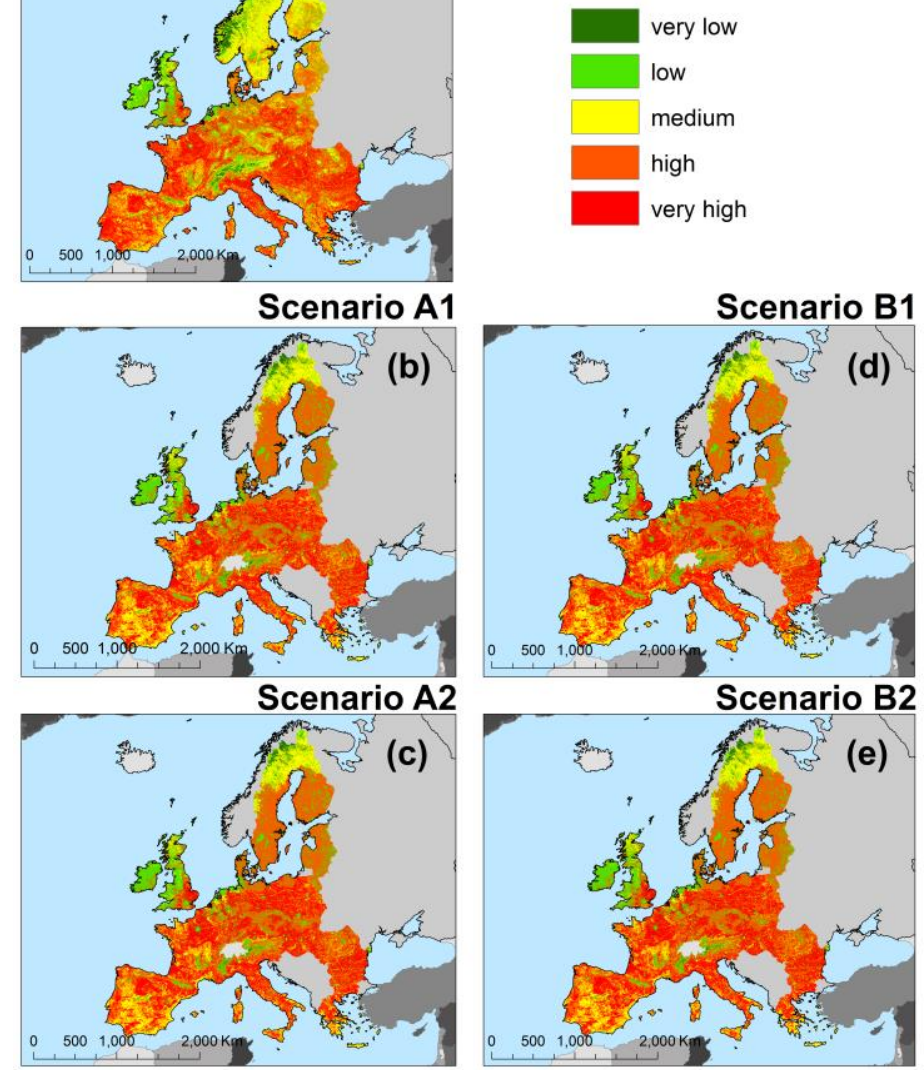

Fig. 10. Spatial distribution of LCFE in Europe during the initial season. (a) Present. (b)

Scenario A1. (c) Scenario A2. (d) Scenario B1. (e) Scenario B2.

In the mid-season, the extremely high degree of LCFE was depicted in the lowlands of southern Europe, but also in the West, North, and East of Europe. In the Alps Range, Pyrenees and Scandinavian Mountains, the degree is low and very low, whereas, in the Carpathians, Dinarics, Scottish, and Apennines Mountains the LCFE is medium. 


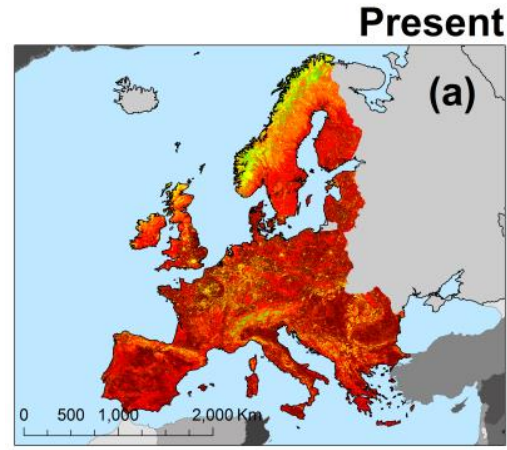

\section{Favorability degree (mid)}
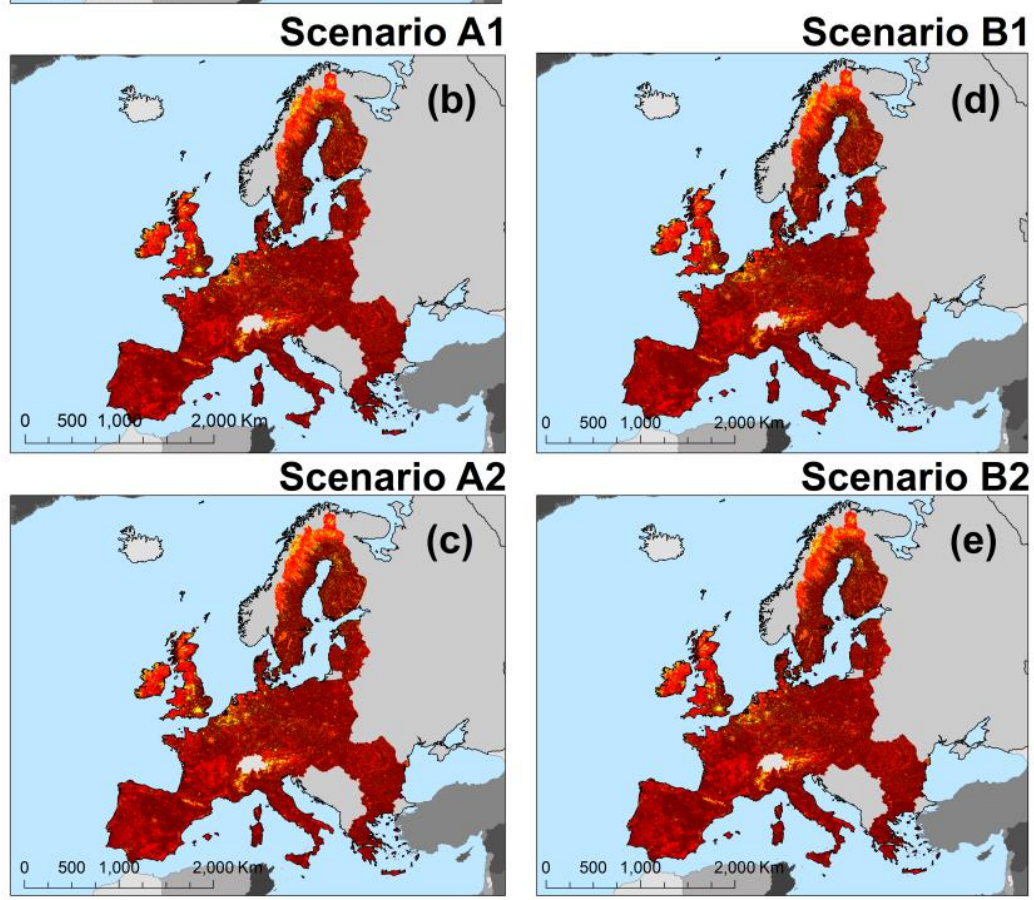

Fig. 11. Spatial distribution of LCFE in Europe during the mid-season. (a) Present.

(b) Scenario A1. (c) Scenario A2. (d) Scenario B1. (e) Scenario B2. 


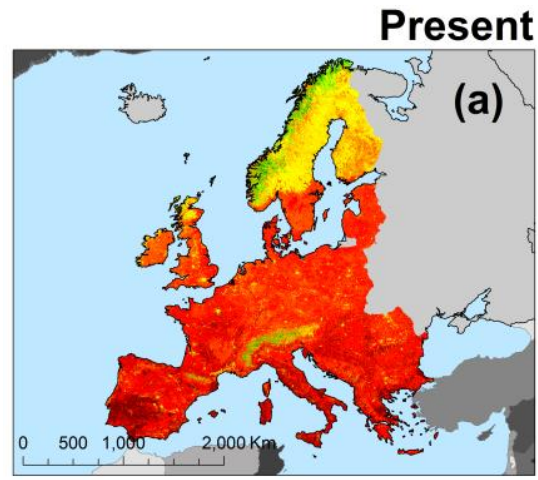

\section{Favorability degree (end)}
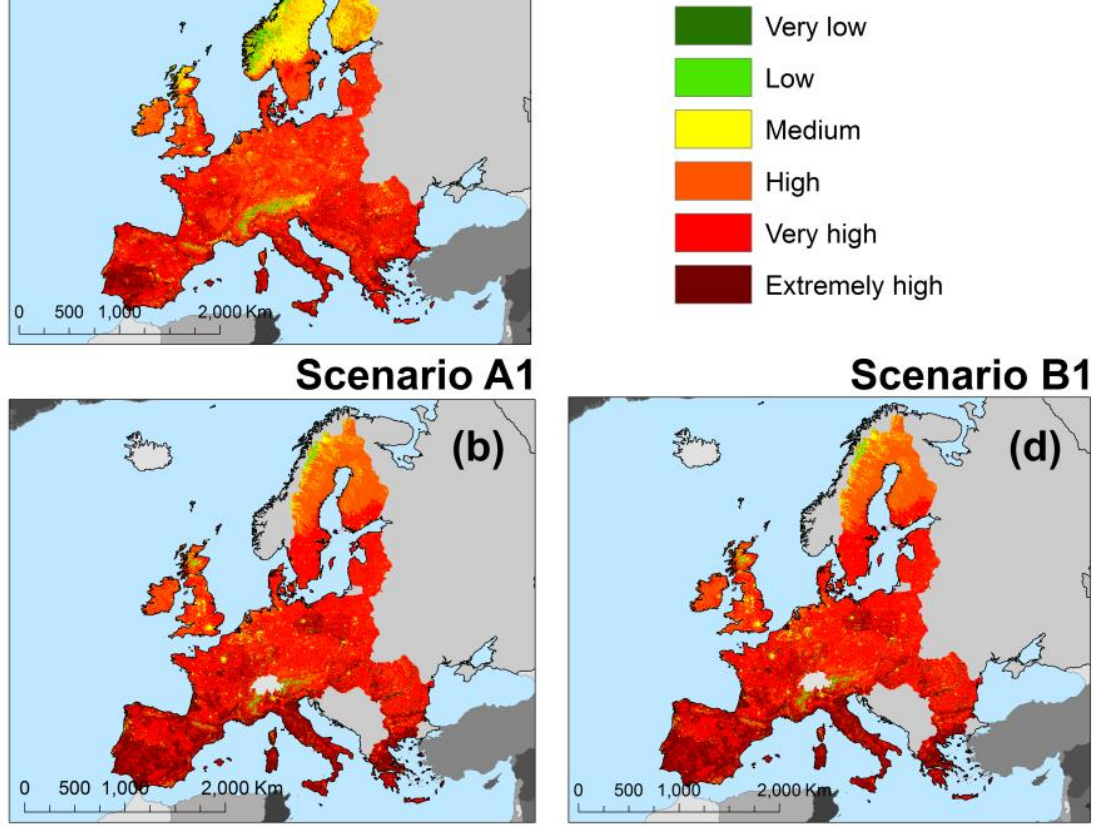

Scenario A2
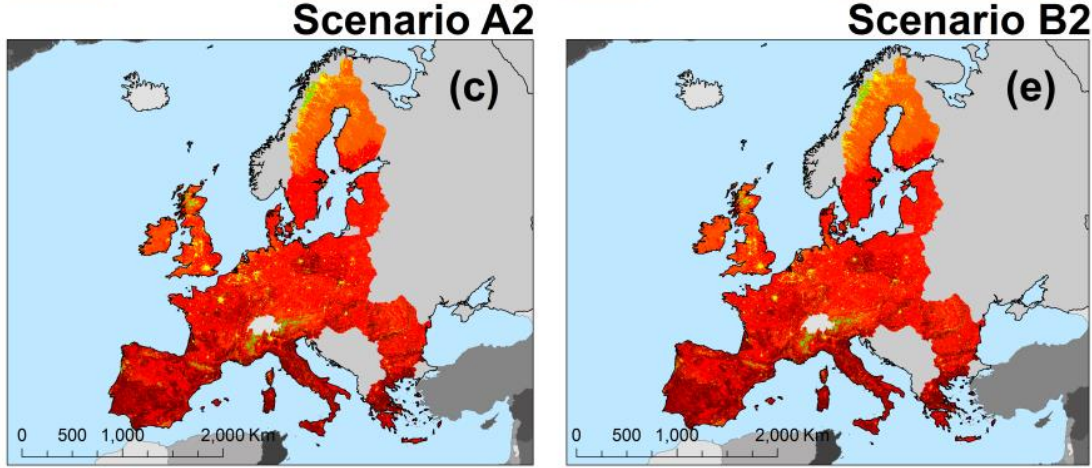

Fig. 12. Spatial distribution of LCFE in Europe during the end season. (a) Present. (b) Scenario A1. (c) Scenario A2. (d) Scenario B1. (e) Scenario B2.

The medium LCFE was found also in the large capitals and cities, e.g. London, Paris, Birmingham, and in the central and western sides of the Scandinavian Peninsula. The future scenarios indicate largest areas with an extremely high degree of the LCFE in the central, South, West, and some eastern sides of the Europe. Figure 11 depicts the favorability degree in Europe related to the mid-season. 
During the end season, the present LCFE map illustrates large areas with high and very high degree for evapotranspiration favorability, while the extremely high LCFE was depicted mainly in the West of Iberian Peninsula, South of Balkan Peninsula, Italian Peninsula, in some places from central Europe, and in the Mediterranean Islands. Medium, low, and very low degree were identified in the Alps Range, Scandinavian Peninsula, North of British Islands, Pyrenees Mountains, East of Sicily and in the Etna Mount. The medium LCFE extends also in the large urban areas, and in the central Iberian Peninsula, South of France, sparsely in the central and East of Europe. The future scenarios show increase of areas with extremely high degree of evapotranspiration favorability, especially in the southern, western, and eastern sides of Europe. The favorability degree in the end season of Europe is presented in Figure 12.

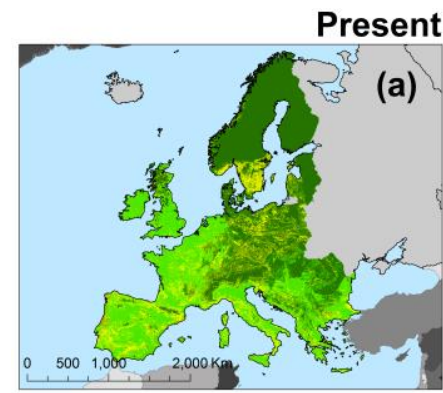

\section{Favorability degree (cold)}
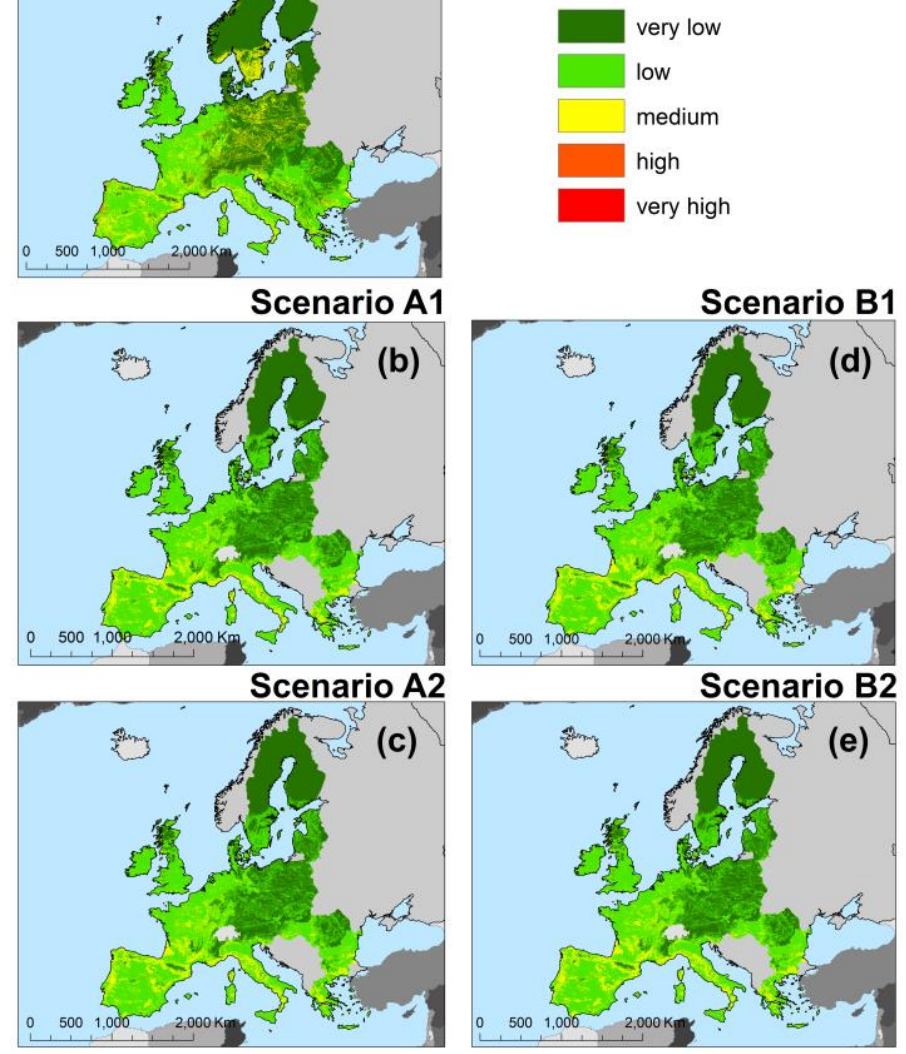

Fig. 13. Spatial distribution of LCFE in Europe during the cold season. (a) Present. (b) Scenario A1. (c) Scenario A2. (d) Scenario B1. (e) Scenario B2.

Very low degree of LCFE is depicted in the cold season mainly in the northern, central, and eastern sides of Europe. The low degree of LCFE is predominantly in the West and South of the continent, while medium LCFE appears in the West of the Iberian Peninsula 
and sparsely in central and northern Europe, in Italian and Balkan Peninsula. This degree class extends also in the South of the Scandinavian Peninsula, but only for the present period. The future scenarios show an increase of low and very low degree in the East and North of Europe, whereas in the West and South of Europe, the medium class increases in the spatial distribution. A remarkable situation about high and very high degree of LCFE could be found only for the present in few locations from South of Italy, South of Balkan Peninsula, around the coastal areas of the Iberian Peninsula, and in the Aegean Islands. Figure 13 depicts the favorability degree in Europe related to the cold season.

\section{DISCUSSION}

The main goal of this paper is to evaluate the seasonal mean air temperature and the seasonal Kc in Europe during 2011-2040 and 2041-2070 and to implement a methodology to identify areas with different degrees of favorability to evapotranspiration. The seasonality in Europe and, in general, in the temperate zone indicates four stages with various characteristics in the climate regime and growth of plants. As a parameter which indicates the exchange between vegetation and atmosphere (Chen et al, 2006), the evapotranspiration parameter is a useful indicator in hydrological and climate studies. First and the most important input for the evapotranspiration calculation is temperature because, without positive values of temperature, lack of energy as a result cannot produce evapotranspiration. Spatial distribution of seasonal mean air temperature is very diversified in Europe, with significant influences of Atlantic Ocean in the West and Mediterranean influences in the South sides, where temperatures are higher than in central, eastern and northern Europe. On the Eastern sides, North of the Black Sea, the high values of seasonal temperature are present also. These higher values of temperature were found in all seasons. A slight increase for the future period (2041-2070) could be observed. Continentality and large parts of land in eastern Europe contribute to the low and negative temperature in the cold season. The North of Europe is influenced by the Arctic cool zone, a fact for which the values of temperature are lower than in other parts of Europe, especially in the cold and initial season. As a consequence of the distribution of temperature in the European territory, evapotranspiration rate highly correlates to the quantity of heat and sunshine energy. For this reason, the southern and western regions of Europe are more susceptible to high evapotranspiration.

Land cover composition is the second factor which affects evapotranspiration, due to different absorption and hydrological exchanges of various vegetation types, and because of the crop calendar. In this sense, the non-vegetative land cover features such as glaciers, urban areas, or bare soil, contribute to evapotranspiration rate much in the mid-season period. In the northern lands of Europe and in the North of British Islands, low values of Kc are observed due to peat bogs areas, heath and moorlands fields. In the mountain areas, glaciers and coniferous forests influence the Kc. The ice covers have values of 0.48 (initial and cold season) and 0.52 (mid-season and end season), especially in the Alps, and the evergreen areas and the coniferous forest have a value 1 in all seasons. This is important because the evapotranspiration expectation could be higher also during the winter.

The future seasonal $\mathrm{K}_{\mathrm{c}}$ does not reach the maximum value such as in the present due to simplified classes of the land cover. Thus, the forest class is not differentiated in the future by the broad-leaved and mixed forests, so one unique class for this type was used for the projections of land cover. The artificial areas are also represented only by one class, which 
included all built-up areas. Due to these simplifications, the future spatial distribution of $\mathrm{Kc}$ that resulted from the scenarios indicate values lower than in the present up to 0.15 in the end season, but the Kc values are still within the range of previous literature studies. Analyzing the seasonal Kc patterns, it was observed that in the A1 scenario, lands with higher Kc are larger than in scenario B1 during all seasons. Comparing scenario A2 with scenario B2, areas with high Kc occupies more territory in scenario B2 than in scenario A2. From the analysis of scenario A1 and scenario B2, it was concluded that scenario A1 has more territory with high values of $\mathrm{Kc}$ in comparison with B2 scenario. The last, between scenarios $\mathrm{A} 2$ and $\mathrm{B} 1$, the analysis of patterns indicates larger areas with high $\mathrm{Kc}$ in scenario A2 than in scenario B1.

Incorporating the seasonal temperature and seasonal Kc of Europe in the $6 \times 6$ matrix as the NISTOR-LCFE method proposes, the favorability degree to evapotranspiration is highly dependent on the spatial distribution of both variables. The extremely high and very high LSCE is predominantly in the mid-season because mean air temperature is high in this season and also vegetation functions are more active than in other seasons. LCFE with very high and extremely high favorability was identified in the initial and end season, while in the cold season, the low and very low LCFE are predominant in Europe. In response to climate change, the future LCFE maps illustrate major changes in the high and very high degree class of favorability.

Even if we do not calculate crop evapotranspiration, the findings carried out through the NISTOR-LCFE method may be compared to the results obtained by Nistor \& PorumbGhiurco (2015), Nistor et al (2016b), Nistor et al (2017a), Nistor et al (2017b) which assess the crop evapotranspiration in different regions of Europe. The above mentioned studies indicate high values of evapotranspiration during the mid-season, with an increase of areas with high and very high crop evapotranspiration. However, the key work of Nistor (2016) related to seasonal $\mathrm{Kc}$ in the Paris metropolitan area represented the base for Kc values decision for this paper.

Our work is not without limitations, considering that the complicated hydrological processes related to evapotranspiration are very complex. Here, we presented a reliable methodology to assess the LCFE at European scale. Based on climate models to extract seasonal temperature and using land cover database to determine the spatial distribution of $\mathrm{Kc}$, the results could be slightly different at the local scale due to missing field measurements of Kc. The large territory of Europe and the multitude of land cover types do not permit us to complete an exhaustive survey using tensiometers and lysimeters. For this reason, we admit to using standard Kc knowing that evapotranspiration rate may fluctuate under the coefficients of evapotranspiration.

\section{CONCLUSIONS}

Spatial distribution of seasonal mean air temperature and seasonal $\mathrm{K}_{\mathrm{c}}$ have been mapped for Europe in two time shifts with an aim to depict different degrees of evapotranspiration favorability using a new spatial-temporal approach. The application of the NISTOR-LCFE method combines climate models and land cover data in an efficient way that can be easily completed in ArcGIS environment. The power of our original method offers an overall view at spatial scale of favorability areas to evapotranspiration without the necessity to execute potential evapotranspiration which requires time and calculations. In addition, the NISTOR-LCFE approach has not been used in previous researches and this outcome may contribute to the specific literature. 
The areas from West, South, and East Europe are susceptible to very high and extremely high degree of evapotranspiration during the mid-season and in the future, these areas would seem to extend. For the same season, the low and very low LCFE overlap to the mountain belts and on the northern territory. The medium LCFE is mainly presented in the initial season and spread over the northern sides of Europe, in the Iberian Peninsula, South of Europe, West-central parts of Europe (e.g. in France), and in the Carpathians Mountains. For an optimization of numerous environmental factors and for good practices in the society for decision making, our maps could be helpful to indicate drought areas during the summer periods, runoff and water surplus calculations, and to set up agricultural management planning.

Our findings fit also with climatology and hydrological sciences, for which further calculations of potential and actual evapotranspiration concerning groundwater vulnerability could be drawn. In this sense, the utilization of climate models and land cover scenarios are an exciting issue for many expertise fields. Future works will focus on water resources quantitative statement under climate change linking also land cover implications. To support the planning for environmental management, we provide out gridded data layers of seasonal temperature and seasonal $\mathrm{Kc}$ through an open access database (https://zenodo.org: 10.5281/zenodo.1193226).

\section{Acknowledgements}

The authors would like to thank Andreas Hamann from Alberta University for the climate model data, European Environmental Agency and Hercules team members for the land cover raster data. Previous affiliation of the corresponding author: Earthresearch Company, Department of Hydrogeology, Cluj-Napoca, Romania.

\section{REFERENCES}

Aguilera, H. \& Murillo, J.M. (2009) The effect of possible climate change on natural groundwater recharge based on a simple model: a study of four karstic aquifers in SE Spain. Environmental Geology, 57(5), 963-974.

Allen, R.G., Pereira, L.S., Raes, D. \& Smith, M. (1998) Crop Evapotranspiration: Guidelines for Computing Crop Water Requirements. FAO Irrigation and Drainage Paper 56. FAO: Rome, pp. 300.

Allen, R.G. (2000) Using the FAO-56 dual crop coefficient method over an irrigated region as part of an evapotranspiration intercomparison study. Journal of Hydrology, 229, 27-41.

Ambas, V.T. \& Baltas, E. (2012) Sensitivity analysis of different evapotranspiration methods using a new sensitivity coefficient. Global NEST Journal, 14(3), 335-343.

Bachu, S. \& Adams, J.J. (2003) Sequestration of CO2 in geological media in response to climate change: capacity of deep saline aquifers to sequester $\mathrm{CO} 2$ in solution. Energy Conversion and Management, 44, 3151-3175.

Brouyère, S., Carabin, G. \& Dassargues, A. (2004) Climate change impacts on groundwater resources: modelled deficits in a chalky aquifer, Geer basin, Belgium. Hydrogeology Journal, 12, 123-134.

Campos, G.E.P., Moran, M.S., Huete, A., Zhang, Y., Bresloff, C., Huxman, T.E. et al. (2013) Ecosystem resilience despite large-scale altered hydroclimatic conditions. Nature, 494, 349-353.

Čenčur Curk, B., Cheval, S., Vrhovnik, P., Verbovšek, T., Herrnegger, M., Nachtnebel, H.P., Marjanović, P., Siegel, H., Gerhardt, E., Hochbichler, E., Koeck, R., Kuschnig, G., Senoner, T., Wesemann, J., Hochleitner, M., Žvab Rožič, P., Brenčič, M., Zupančič, N., Bračič Železnik, B., Perger, L., Tahy, A., Tornay, E.B., Simonffy, Z., Bogardi, I., Crăciunescu, A., Bilea, I.C., Vică, P., Onuţu, I., Panaitescu, C., Constandache, C., Bilanici, A., Dumitrescu, A., Baciu, M., Breza, T., Marin, L., Draghici, C., Stoica, C., Bobeva, A., Trichkov, L., Pandeva, D., Spiridonov, V., 
Ilcheva, I., Nikolova, K., Balabanova, S., Soupilas, A., Thomas, S., Zambetoglou, K., Papatolios, K., Michailidis, S., Michalopoloy, C., Vafeiadis, M., Marcaccio, M., Errigo, D., Ferri, D., Zinoni, F., Corsini, A., Ronchetti, F., Nistor, M.M., Borgatti, L., Cervi, F., Petronici, F., Dimkić, D., Matić, B., Pejović, D., Lukić, V., Stefanović, M., Durić, D., Marjanović, M., Milovanović, M., Boreli-Zdravković, D., Mitrović, G., Milenković, N., Stevanović, Z. \& Milanović, S. (2014) CCWARE Mitigating Vulnerability of Water Resources under Climate Change. WP3 - Vulnerability of Water Resources in SEE, Report Version 5. URL: http://www.ccware.eu/outputdocumentation/output-wp3.html.

Chaieb, A., Rebai, N., Ghamni, M.A., Moussi, A. \& Bouaziz S. (2017) Spatial analysis of river longitudinal profils to cartography tectonic activity in Kasserine Plain Tunisia. Geographia Technica 12(2): 30-40.

Chen, S.B., Liu, Y.F. \& Thomas, A. (2006) Climatic change on the Tibetan plateau: potential evapotranspiration trends from 1961 to 2000. Climatic Change, 76, 291-319.

Cheval, S., Dumitrescu, A. \& Barsan, M.V. (2017) Variability of the aridity in the South-Eastern Europe over 1961-2050. Catena, 151, 74-86.

Copernicus Land Monitoring Services. (2012) CORINE Land Cover of Europe. URL: http://land.copernicus.eu/ (accessed 21 July 2016).

Dong, P., Wang, C. \& Ding, J. (2013) Estimating glacier volume loss used remotely sensed images, digital elevation data, and GIS modelling. International Journal of Remote Sensing, 34(24), 8881-8892.

Elfarrak, H., Hakdaoui, M. \& Fikri, A. (2014) Development of Vulnerability through the DRASTIC Method and Geographic Information System (GIS) (Case Groundwater of Berrchid), Morocco. Journal of Geographic Information System, 6, 45-58.

European Environmental Agency. (2007) Land-use scenarios for Europe: qualitative and quantitative analysis on a European scale. ISSN 1725-2237. EEA Technical report No 9/2007.

Gao, G., Chen, D., Xu, C.Y. \& Simelton, E. (2007) Trend of estimated actual evapotranspiration over China during 1960-2002. J. Geophys. Res., 112(D11120), 1-8, DOI: 10.1029/2006JD008010.

Gao, G., Xu, C.Y., Chen, D. \& Singh, V.P. (2012) Spatial and temporal characteristics of actual evapotranspiration over Haihe River basin in China. Stoch. Environ. Res. Risk Assess., 26, 655669.

Güçlü, Y.S., Subyani, A.M. \& Şen, Z. (2017) Regional fuzzy chain model for evapotranspiration estimation. Journal of Hydrology, 544, 233-241.

Gowda, P.H., Chavez, J.L., Colaizzi, P.D., Evett, S.R., Howell, T.A. \& Tolk, J.A. (2008) ET mapping for agricultural water management: present status and challenges. Irrigation Science, 26(3), 223237.

Grimmond, C.S.B. \& Oke, T.R. (1999) Evapotranspiration rates in urban areas, Impacts of Urban Growth on SurfaceWater and Groundwater Quality. Proceedings of IUGG 99 Symposium HSS. Birmingham, July 1999.

Hamann, A. \& Wang, T.L. (2005) Models of climatic normals for genecology and climate change studies in British Columbia. Agricultural and Forest Meteorology, 128, 211-221.

Hamann, A., Wang, T., Spittlehouse, D.L. \& Murdock, T.Q. (2013) A comprehensive, high-resolution database of historical and projected climate surfaces for western North America. Bulletin of the American Meteorological Society, 94, 1307-1309.

Haeberli, W.R., Frauenfelder, R., Hoelzle, M. \& Maisch, M. (1999) On rates and acceleration trends of global glacier mass changes. Geografiska Annaler, Series A, Physical Geography, 81A, 585595 .

IPCC. (2001) Climate change 2001: the scientific basis. In: Houghton, J.T., Ding, Y., Griggs, D.J., Noguer, M., van der Linden, P.J., Dai, X. (Eds), Contribution of Working Group I to the Third Assessment Report of the Intergovernmental Panel on Climate Change. Cambridge University Press: Cambridge and New York, New York, pp. 881.

Jiménez Cisneros, B.E., Oki, T., Arnell, N.W., Benito, G., Cogley, J.G., Döll, P., Jiang, T. \& Mwakalila, S.S. (2014) Freshwater resources. In: Field, C.B., Barros, V.R., Dokken, D.J., Mach, 
K.J., Mastrandrea, M.D., Bilir, T.E., Chatterjee, M., Ebi, K.L., Estrada, Y.O., Genova, R.C., Girma, B., Kissel, E.S., Levy, A.N., MacCracken, S., Mastrandrea, P.R., White, L.L. (Eds.), Climate Change 2014: Impacts, Adaptation, and Vulnerability. Part A: Global and Sectoral Aspects. Contribution of Working Group II to the Fifth Assessment Report of the Intergovernmental Panel on Climate Change. Cambridge University Press, Cambridge, United Kingdom and New York, USA, pp. 229-269.

Kargel, J.S., Abrams, M.J., Bishop, M.P., Bush, A., Hamilton, G., Jiskoot, H., Kääb, A., Kieffer, H.H., Lee, E.M., Paul, F., Rau, F., Raup, B., Shroder, J.F., Soltesz, D., Stainforth, S., Stearns, L. \& Wessels, R. (2005) Multispectral imaging contributions to global land ice measurements from space. Remote Sensing of Environment, 99(1), 187-219.

Kløve, B., Ala-Aho, P., Bertrand, G., Gurdak, J.J., Kupfersberger, H., Kværner, J., Muotka, T., Mykrä, H., Preda, E., Rossi, P., Bertacchi Uvo, C., Velasco, C. \& Pulido-Velazquez, M. (2014) Climate change impacts on groundwater and dependent ecosystems. Journal of Hydrology, 518, 250-266.

Kottek, M., Grieser, J., Beck, C., Rudolf, B. \& Rubel, F. (2006) World Map of the Köppen-Geiger climate classification updated. Meteorologische Zeitschrift, 15(3), 259-263.

Ladányi, Zs., Blanka, V., Meyer, B., Mezősi, G. \& Rakonczai, J. (2015) Multi-indicator sensitivity analysis of climate change effects on landscapes in the Kiskunság National Park, Hungary. Ecological Indicators, 58, 8-20.

Li, K.Y., Coe, M.T., Ramankutty, N. \& De Jong, R. (2007) Modeling the hydrological impact of landuse change in West Africa. Journal of Hydrology, 337, 258-268.

Loàiciga, H.A., Maidment, D.R. \& Valdes, J.B. (2000) Climate-change impacts in a regional karst aquifer, Texas, USA. Journal of Hydrology, 227, 173-194.

Mbogga, M.S., Hamann, A. \& Wang, T. (2009) Historical and projected climate data for natural resource management in western Canada. Agricultural and Forest Meteorology, 149, 881-890.

Mitchell, T.D. \& Jones, P.D. (2005) An improved method of constructing a database of monthly climate observations and associated high-resolution grids. International Journal of Climatology, $25,693-712$.

Nistor, M.M. (2013) Geological and geomorphological features of Kenai and Chugach Mountains in Whittier Area, Alaska. STUDIA UBB GEOGRAPHIA, LVIII(1), 27-34.

Nistor, M.M. \& Petcu, I.M. (2014) The role of glaciers in the evolution of Prince William Sound landscape ecosystems, Alaska. STUDIA UBB AMBIENTUM, LIX(1-2), 97-109.

Nistor, M.M., Ronchetti, F., Corsini, A., Cervi, F., Borgatti, L., Errigo, D. \& Marcaccio, M. (2014) Vulnerability of groundwater in fractured aquifers, under climate and land use change in Northern Apennines. National Meeting on Hydrogeology, Abstract volume Flowpath 2014, Viterbo June 18-20, 152-153.

Nistor, M.M. \& Petcu, M.I. (2015) Quantitative analysis of glaciers changes from Passage Canal based on GIS and satellite images, South Alaska. Applied Ecology and Environmental Research, 13(2), 535-549.

Nistor, M.M. \& Porumb-Ghiurco, G.C. (2015) How to compute the land cover evapotranspiration at regional scale? A spatial approach of Emilia-Romagna region. GEOREVIEW Scientific Annals of Ştefan cel Mare University of Suceava, Geography Series, 25(1), 38-54.

Nistor, M.M. (2016) Mapping evapotranspiration coefficients in the Paris metropolitan area. GEOREVIEW Scientific Annals of Ştefan cel Mare University of Suceava, Geography Series, 26(1), 138-153.

Nistor, M.M., Dezsi, St., Cheval, S. \& Baciu M. (2016a) Climate change effects on groundwater resources: a new assessment method through climate indices and effective precipitation in Beliş district, Western Carpathians. Meteorological Applications, 23, 554-561.

Nistor, M.M., Gualtieri, A.F., Cheval, S., Dezsi, St. \& Boţan, V.E. (2016b) Climate change effects on crop evapotranspiration in the Carpathian Region from 1961 to 2010. Meteorological Applications, 23, 462-469. 
Nistor, M.M., Cheval, S., Gualtieri, A., Dumitrescu, A., Boţan, V.E., Berni, A., Hognogi, G., Irimuş, I.A. \& Porumb-Ghiurco, C.G. (2017a) Crop evapotranspiration assessment under climate change in the Pannonian basin during 1991-2050. Meteorological Applications, 24, 84-91.

Nistor, M.M. \& Mîndrescu, M. (2017) Climate change effect on groundwater resources in EmiliaRomagna region: An improved assessment through NISTOR-CEGW method. Quaternary International, https://doi.org/10.1016/j.quaint.2017.11.018.

Nistor, M.M., Ronchetti, F., Corsini, A., Cheval, S., Dumitrescu, A., Rai, P.K., Petrea, D., \& Dezsi, Şt. (2017b) Crop evapotranspiration variation under climate change in South East Europe during 1991-2050. Carpathian Journal of Earth and Environmental Sciences, 12(2), 571-582.

Öztürk, M., Copty N., K. \& Saysel A., K. (2013) Modeling the impact of land use change on the hydrology of a rural watershed. Journal of Hydrology, 497, 97-109.

Oerlemans, J. (2005) Extracting a Climate Signal from 169 Glacier Records. Science, 308, 675-677.

Parmesan, C. \& Yohe, G. (2003) A globally coherent fingerprint of climate change impacts across natural systems. Nature, 421(2), 37-42.

Prăvălie, R., Sîrodoev, I. \& Peptenatu, D. (2014) Detecting climate change effects on forest ecosystems in Southwestern Romania using Landsat TM NDVI data. Journal of Geographical Sciences, 24, 815-832.

Rosenberry, D.O., Winter, T.C., Buso, D.C. \& Likens, G.E. (2007) Comparison of 15 evaporation methods applied to a small mountain lake in the northeastern USA. Journal of Hydrology, 340, 149-166.

Schulp, C.J.E., Tieskens, K.F., Sturck, J., Fuchs, R., van der Zanden, E.H., Schrammeijer, E. \& Verburg, P.H. (2015) EU scale analysis of future cultural landscape dynamics. Report no. 1, WP 5 Fine- and broad-scale modelling of future landscapes.

Shahgedanova, M., Stokes, C.R., Gurney, S.D. \& Popovnin, V. (2005) Interactions between mass balance, atmospheric circulation, and recent climate change on the Djankuat Glacier, Caucasus Mountains, Russia. Journal of Geophysical Research, 110(D16107), 1-12.

Yustres, Á., Navarro, V., Asensio, L., Candel, M. \& García, B. (2013) Groundwater resources in the Upper Guadiana Basin (Spain): a regional modelling analysis. Hydrogeology Journal, 21, 11291146.

Xie, X., Li, Y.X., Li, R., Zhang, Y., Huo, Y., Bao, Y. \& Shen, S. (2013) Hyperspectral characteristics and growth monitoring of rice (Oryza sativa) under asymmetric warming. International Journal of Remote Sensing, 34(23), 8449-8462. 